\title{
Optimal-Efficiency Control for Constant-Power Operation of Phase-Decoupling Permanent-Magnet Brushless Motor Drives
}

\author{
C.C. Chan, J.Z. Jiang, W. Xia, K.T. Chau, and M.L. Zhu \\ Department of Electrical and Electronic Engineering \\ The University of Hong Kong \\ Pokfulam Road, Hong Kong
}

\begin{abstract}
In this paper, a control approach to optimize the system efficiency of phase-decoupling (PD) permanent-magnet (PM) brushless motor drives during constant-power operation is presented. The approach is to adaptively adjust the advanced conduction angle to minimize the total system losses for a given operation point in the constant-power region. The corresponding minimum total losses are determined by minimizing the input current for a fixed voltage source. Both computer simulation and experimental results are given for illustration.
\end{abstract}

\section{INTRODUCTION}

In order to fulfil the stringent requirements of modern drive systems, researchers are actively engaged to develop motor drives with high efficiency, high power density and good dynamical performance. Recently, a novel design concept of permanent-magnet (PM) brushless motors has been developed [1]-[3]. The key of this concept is to provide an independent magnetic flux path of each phase of these motors, so-called phase-decoupling (PD) PM brushless motors.

Due to the phase-decoupling nature, these PM brushless motors possess several distinct advantages over their conventional counterparts - namely, reduction of magnetic yoke, reduction of winding overhang, minimization of cogging torque, and improvement of controllability [1]. Moreover, they can be implemented into various topologies such as rectangular-fed (brushless DC), sinusoidal-fed (brushless AC), surface-magnet, interior-magnet, inner-rotor and outer-rotor alternatives.

Because of their high power density, high efficiency and high controllability, PD PM brushless motors have been successfully applied to experimental electric vehicles (EVs) [2]. However, similar to conventional PM brushless motors, they suffer from the problem of the loss of current regulation during high-speed constant-power operation. It should be noted that wide-range constant-power operation is highly desirable for EV applications because it can minimize the required motor drive ratings, and facilitate high-speed cruising.

By incorporating the well-known $d-q$ coordinate transformation, flux-weakening control has been accepted to achieve constant-power operation of PM brushless AC motor drives, including the interior-magnet type with saliency and surface-magnet type without saliency [4], [5]. The reason of its inapplicability to PM brushless DC motor drives is due to the fact that the corresponding waveforms are no longer sinusoidal and thus the $d-q$ coordinate transformation becomes ill-suited.

The improvement of torque-speed operating locus of PM brushless DC motor drives was attempted by phase shifting the inverter switch conduction intervals with respect to the induced EMF waveforms [6], [7]. However, the improvement is accompanied by increases in the pulsating torque.

Very recently, a novel control technique has been proposed to allow for high-speed constant-power operation of PM brushless DC motor drives [3]. The key is to purposely employ the transformer EMF to oppose the rotational EMF in such a way that the loss of current regulation can be avoided at high speeds. Compared with conventional flux-weakening control, this approach has some distinct advantages: it can readily be applied to PM brushless DC motor drives, especially the PD types; it can be implemented without the use of $d-q$ coordinate transformation; and it possesses low torque ripple throughout the high-speed constant-power region.

Although PM brushless motor drives inherently possess high efficiency, their system efficiency can be further improved by some control techniques [8]. For EV applications, optimal-efficiency control is particularly essential because the energy resource is limited by the onboard batteries.

The purpose of the paper is to present an optimalefficiency control scheme for constant-power operation of phase-decoupling PM brushless DC motor drives. The key is to adaptively adjust the advanced conduction angle to minimize the total system losses for a given operation point in the constant-power region.

In Section II, the constant-power operation strategy is interpreted using a 5-phase 22-pole phase-decoupling PM brushless DC motor. The newly-developed optimalefficiency control technique is detailed in Section III. After the description of implementation in Section IV, both computer simulation and experimental verification are given in Section V. 


\section{CONSTANT-POWER OPERATION STRATEGY}

The constant-power operation strategy is interpreted based on a 5-phase 22-pole phase-decoupling PM brushless DC motor. Since the mutual inductance is practically eliminated and winding resistance is negligible, the voltage equation of the motor can be expressed as

$$
\begin{aligned}
v_{j}\left(\omega t+\theta_{o}-\frac{(j-1) \pi}{5}\right)= & L \frac{d i,\left(\omega t+\theta_{o}-\frac{(j-1) \pi}{5}\right)}{d t} \\
& +e_{j}\left(\omega t+-\frac{(j-1) \pi}{5}\right)
\end{aligned}
$$

where $v_{j}$ is the applied voltage, $L \frac{d i_{j}}{d t}$ is the transformer $\mathrm{EMF}, e_{j}$ is the rotational EMF, $i_{j}$ is the phase current, $\omega$ is the angular frequency, $\theta_{0}$ is the advanced conduction angle, and $j=1, \ldots, 5$.

As shown in Fig. 1, only the operating waveforms of the first half cycle are described while those of another half cycle are very similar due to the nature of symmetry. When the motor operates in the high-speed constant-power region, the rotational EMF becomes larger than the applied voltage. To prevent from saturation of the current regulator, a negative transformer EMF is needed to oppose the rotational EMF. This negative transformer EMF is produced by advancing the conduction angle, namely $\theta_{\circ}$, between the phase current and rotational EMF. In the interval 1-2, the applied voltage is larger than the rotational EMF so that the phase current increases and reaches its highest value. In the interval 2-3, the applied voltage is smaller than the rotational EMF. Within this interval, the phase current decreases and hence a negative transformer EMF is produced. Since this negative transformer EMF opposes the rotational EMF, constantpower operation becomes achievable at high speeds. It should be noted that the use of the transformer EMF concept does not restrict to any particular current shapes, and provides an analytical tool for the formulation of motor current and torque during constant-power operation.
Theoretically, the maximum operating speed of the motor occurs at $\theta_{o}=90^{\circ}$. In fact, the limit of high-speed constantpower operation is governed by the transformer EMF, hence determined by the motor inductance and operating frequency.

The cogging torque of the motor is minimized by using the fractional number of slots per pole per phase structure. At any operating point, the phase current is always synchronous with the corresponding rotational EMF. As the motor torque is developed by the interaction of the phase current and rotational EMF, this motor can provide a minimum torque ripple throughout the operating range.

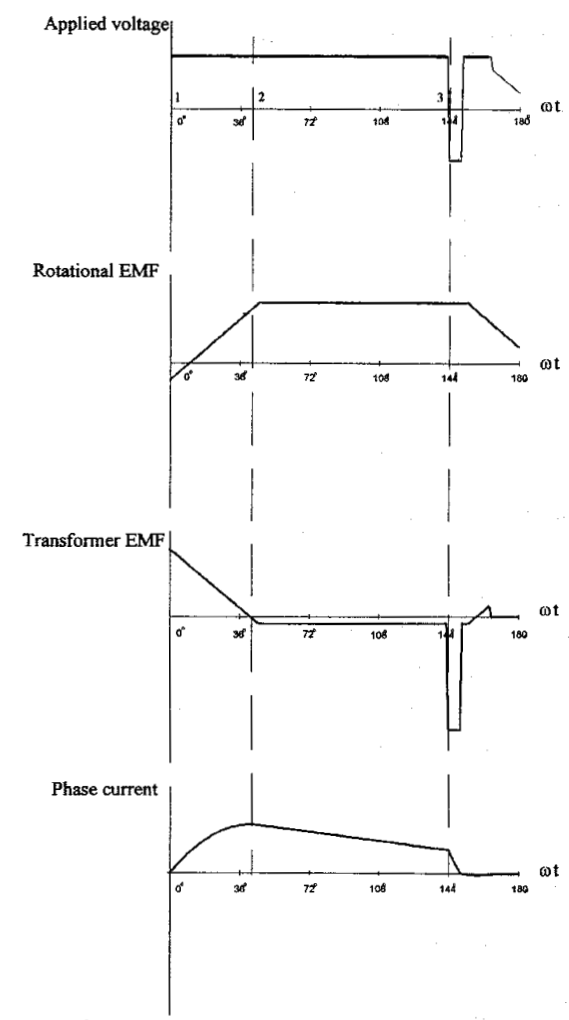

Fig. 1. Waveforms of constant-power operation.

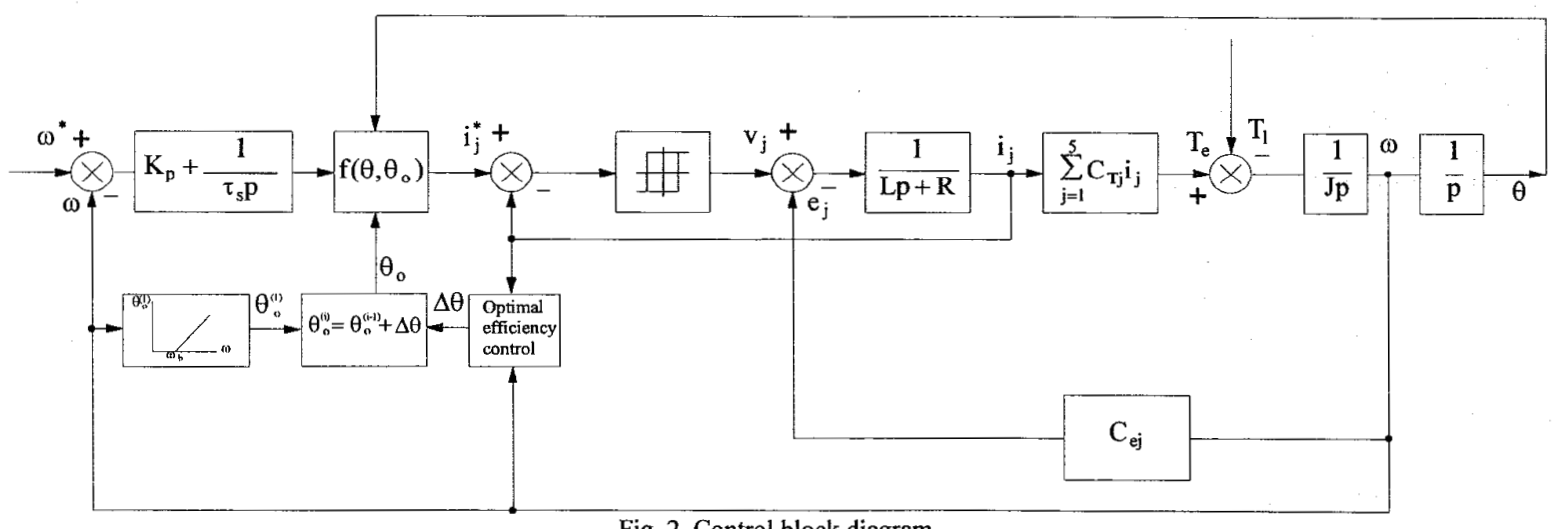

Fig. 2. Control block diagram 


\section{OPTIMAL-EFFICIENCY CONTROL}

Either neglecting the existence of core loss or assuming constant core loss, the motor drive operates at maximum torque per ampere is optimally efficient because of the minimization of copper loss. However, this approximation can no longer be acceptable for high-performance motor drives. In order to achieve optimal-efficiency control during constant-power operation, a new technique is developed which can optimize the system efficiency of the whole drive system.

The proposed optimal-efficiency control scheme is to adaptively adjust the advanced conduction angle in such a way that the input power is minimum for a given output power. The minimization of input power is accomplished by minimizing the input current for a fixed input voltage. Since the instantaneous phase currents have already been fedback for a hysteresis current controller, the input current can be easily determined by summing the magnitudes of all phase currents. It should be noted that the positive and negative signs of phase currents indicate the currents from the upperhalf and lower-half of the voltage source, respectively.

The closed-loop optimal-efficiency control block diagram of the motor drive is illustrated in Fig. 2. The optimalefficiency control block on-line generates the increment of advanced conduction angle $\Delta \theta$ which is used to iteratively modify the advanced conduction angle $\theta_{o}$. The corresponding initial value $\theta_{o}^{(1)}$ is determined by the model given in Fig. 3. When the motor speed $\omega$ is lower than the base speed $\omega_{b}$, numerically $n$ is less than $500 \mathrm{rpm}, \theta_{o}^{(1)}$ is always set to zero. As the motor operates above $\omega_{b}$ for constant-power operation, the value of $\theta_{o}^{(1)}$ is governed by a segment of straight line. To facilitate the generality, the slope of the line is optimistically chosen so as to guarantee constant-power operation over the desired high-speed range.

The algorithm of optimal-efficiency control for constantpower operation is explained using the flowchart shown in Fig. 4. Once an interruption occurs, the motor speed $\omega$ is compared with the speed command $\omega^{*}$. If the difference is larger than a predefined experimental tolerance $k_{1}$, it indicates that the steady state has not reached and no modification is taken, $\Delta \theta=0$. Otherwise, the summation of the magnitudes of all phase currents is carried out which stands for the new input power $W_{\text {new }}$. Comparing with the previous input power $W_{\text {old }}$, the difference is denoted as $\Delta W$. If it is within a predefined experimental tolerance $k_{2}, \Delta \theta$ is set to zero. Otherwise, there are two cases to be considered. If $W_{n e w}$ has increased, the searching direction is reversed by inverting the sign of $\Delta \theta$. On the contrary, the search continues with the same $\Delta \theta$.
A typical searching trajectory of $\theta_{o}$ for optimal-efficiency operation is illustrated in Fig. 5. At a particular steady-state constant-power operating point, $\mathrm{X}$ is determined from the model of $\theta_{o}^{(1)}$ shown in Fig. 3. Based on the self-searching algorithm shown in Fig. 4, $\mathrm{Y}$ is reached where the input power, equivalent to the sum of the magnitudes of all phase currents, is minimum.

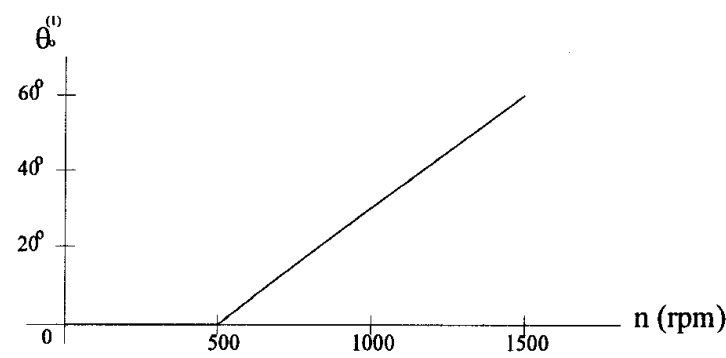

Fig. 3. Model of initial advanced conduction angle.

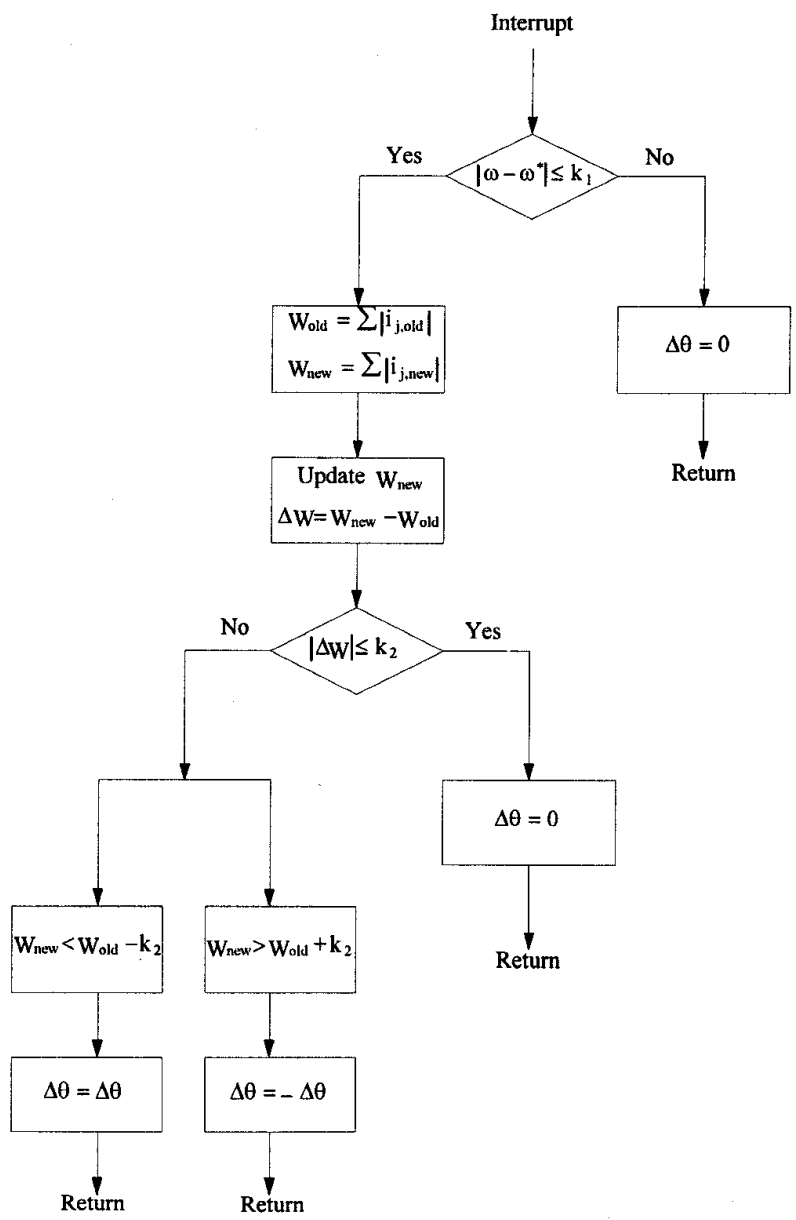

Fig. 4. Flowchart of optimal-efficiency control. 
It should be noted that the proposed optimal-efficiency control approach does not depend on a complicated loss model of the motor. Because of its adaptive on-line search, the approach is insensitive to variations in the motor parameters and operating environments, such as temperature, windage and friction changes.

Apart from achieving optimal-efficiency control during constant-power operation, the torque ripple should be kept minimum. Fig. 6 illustrates the instantaneous torque at the speed of $1500 \mathrm{rpm}$, three times the base speed, where the advanced conduction angle is selected as $52^{\circ}$. It can be seen that the corresponding torque ripple is less than $13 \%$ of the reference value, which is actually the worst case throughout the 1500-rpm speed range. Compared with those results illustrated in [7], the pulsating torque of the proposed motor drive is considerably reduced.

In order to illustrate the effectiveness of the proposed control scheme, a comparative evaluation of the input power, equivalent to sum of the magnitudes of all phase currents, with the initial advanced conduction angle $\theta_{\text {ini }}$ and the optimal-efficiency angle $\theta_{\text {opt }}$ is carried out. The evaluation results throughout the whole constant-power region are shown in Fig. 7. It can be seen that the total input current can be significantly decreased by adaptively adjusting the advanced conduction angle $\theta_{\mathrm{o}}$.

\section{Torque $(\mathrm{Nm})$}

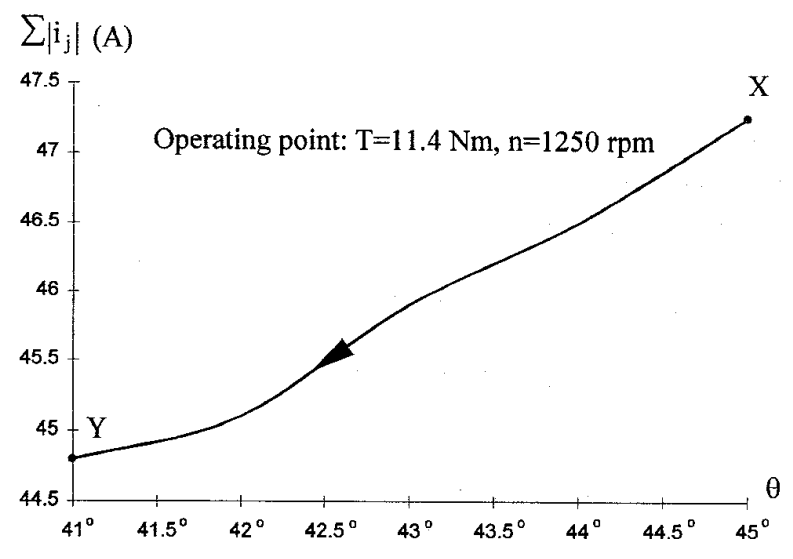

Fig. 5. Adaptive searching trajectory.

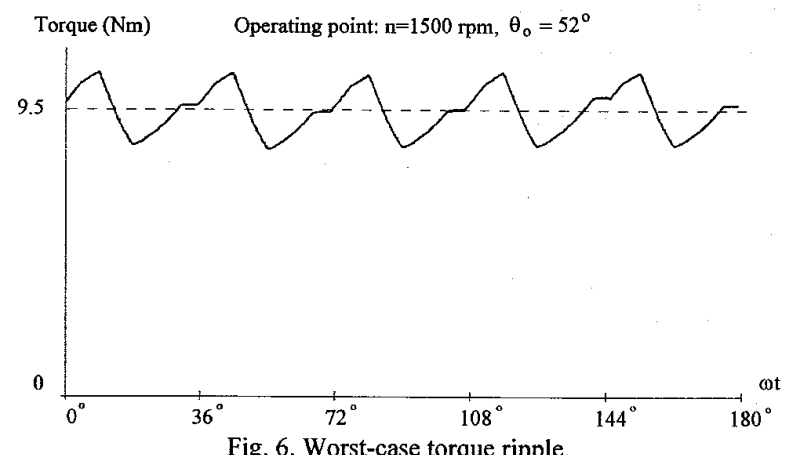

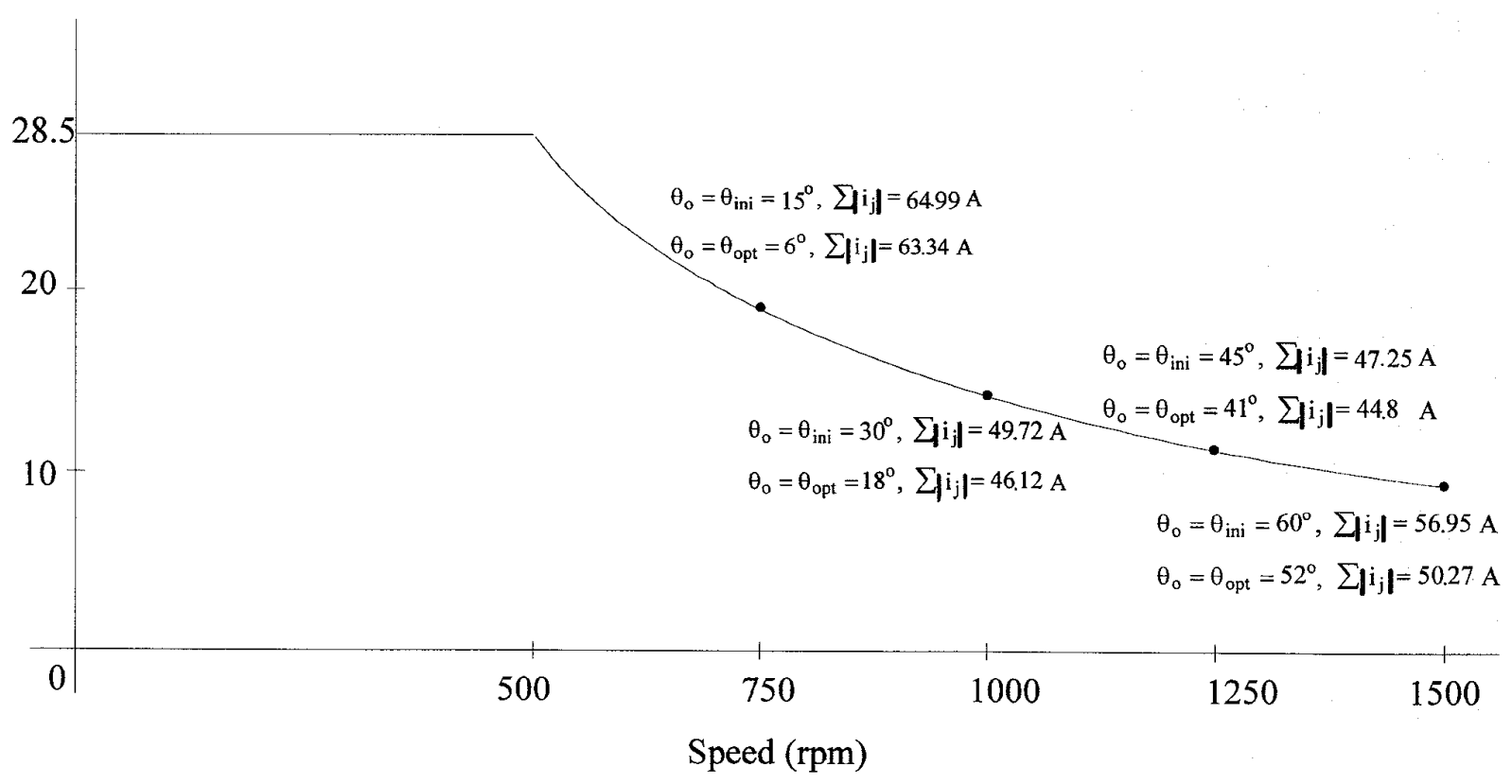

Fig. 7. Evaluation of initial and optimal operation. 


\section{IMPLEMENTATION}

The hardware implementation of the optimal-efficiency controller for the proposed motor drive is illustrated in Fig. 8. A powerful single-chip microcontroller, Intel $80 \mathrm{C} 196 \mathrm{KC}$, is adopted to implement all necessary control functions. This microcontroller possesses built-in ROM or EPROM, RAM, high-speed inputs (HSI), high-speed outputs (HSO), A/D converter with sample/hold (ACH), I/O ports, PWM output, timers, up/down counter with capture, full duplex serial port, interrupt sources, etc.

As shown in Fig. 8, an optical incremental position encoder mounted on the motor shaft generates three pulse trains, namely signals $P_{1}, P_{2}$ and $Z$. These signals are then fed into the HSI of the microcontroller to calculate the motor speed. Motor phase currents are sensed by Hall-effect transducers and the corresponding analog signals are fed into the microcontroller via the $\mathrm{ACH}$, and the hysteresis current controller (HCC). Based on these speed and current feedback signals, the $\theta_{0}$ generator produces the corresponding advanced conduction angle $\theta_{0}$, which is then outputted as a logic signal via the HSO. According to the error between the speed command $\omega^{*}$ and the speed feedback, the proportionalintegral (PI) regulator generates the current reference signals $\mathrm{i}_{\mathrm{j}}^{*}$ for the HCC. Incorporating the logic signals from the $\mathrm{HSO}$ and the $\mathrm{HCC}$, the switching signal generator produces proper switching signals $T_{1}, T_{2}, T_{3}, T_{4}, T_{5}$ for the 5-phase inverter. This inverter consists of ten sets of power switching devices, and is supplied by two sets of DC voltage source.

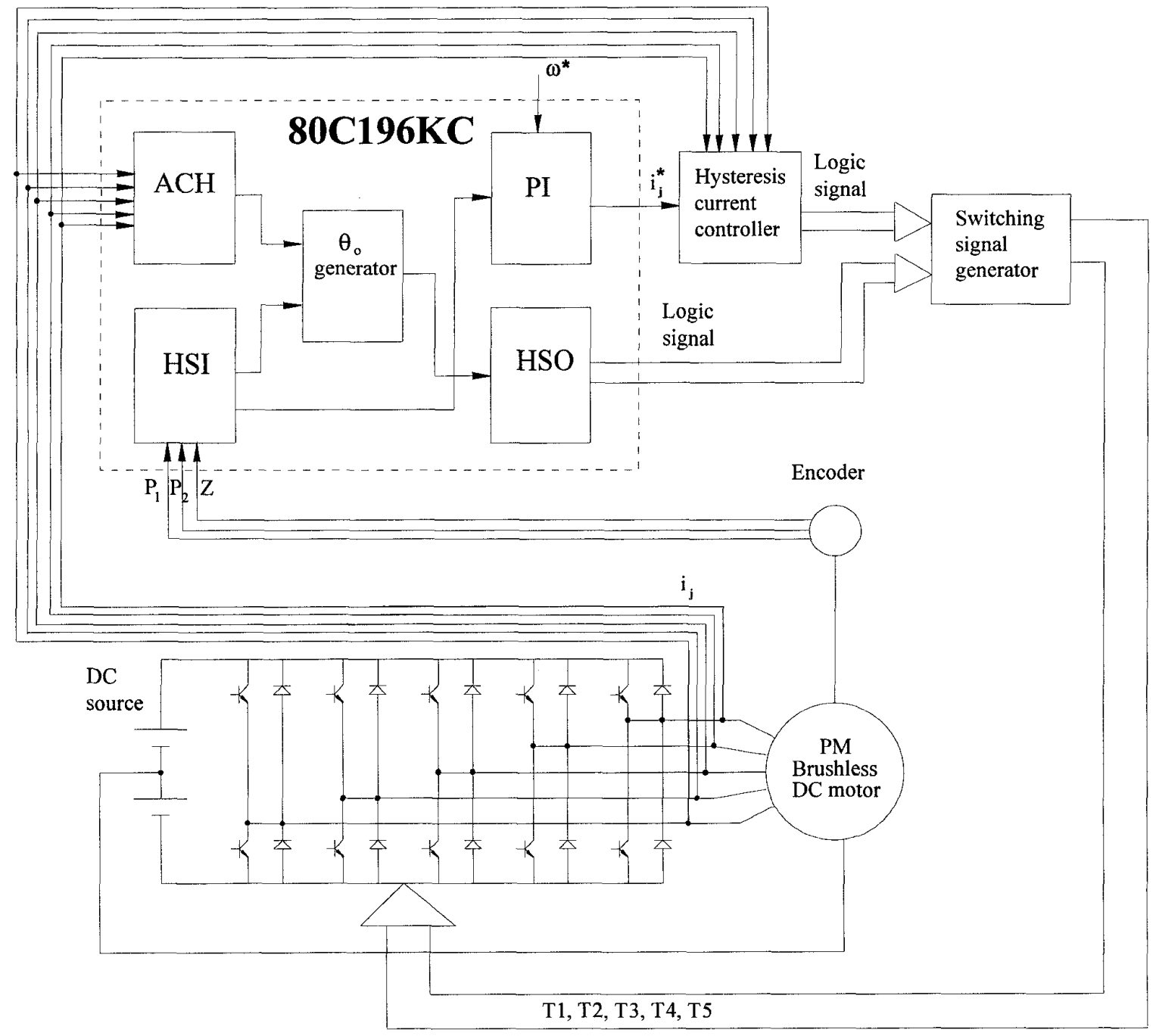

Fig. 8. Hardware implementation. 


\section{RESULTS}

Both computer simulation and experimental results are given to illustrate the proposed approach. The technical data of the experimental motor is listed in Table I.

Since the motor current is the key parameter to illustrate the operating principle, the simulated and experimental current waveforms with the motor speed of $1200 \mathrm{rpm}$, torque of $11.88 \mathrm{Nm}$ and advanced conduction angle of $40^{\circ}$ are shown in Fig. 9(a). and (b), respectively. On the other hand, those waveforms for $1500 \mathrm{rpm}, 9.8 \mathrm{Nm}$ and $58^{\circ}$ are shown in Fig. 10. Good agreement between these simulated and experimental waveforms verifies that the proposed approach works well during constant-power operation.

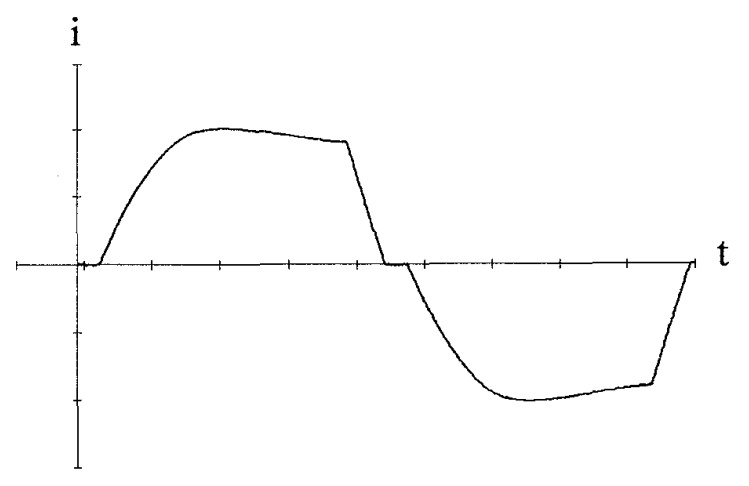

(a)

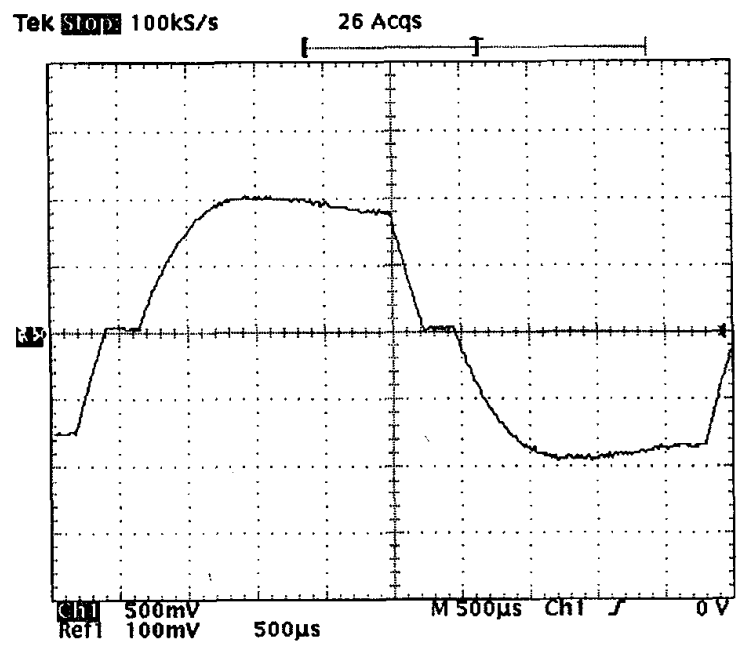

(b)

Fig. 9. Current waveforms at $1200 \mathrm{rpm}(10 \mathrm{~A} / \mathrm{div}, 500 \mu \mathrm{s} / \mathrm{div})$. (a) Simulation. (b) Experimental.
From these current waveforms, it can be found that the negative slope of the interval 2-3, as defined in Fig. 1, of the waveform shown in Fig. 9 is smaller than that shown in Fig. 10. This negative slope effectively causes the transformer EMF to oppose the rotational EMF during high-speed constant-power operation. Thus, the higher the motor speed is desired for constant-power operation, the larger the advanced conduction angle is required, the steeper the negative slope of the current waveform is resulted, hence the higher the transformer EMF is generated.

As shown in Fig. 10, it can be seen that the negative slope can be further increased which indicates that the speed limit for constant-power operation can be further extended and beyond three times the base speed.

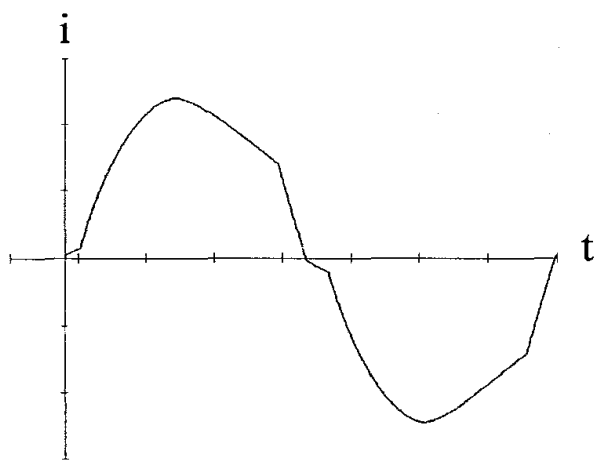

(a)

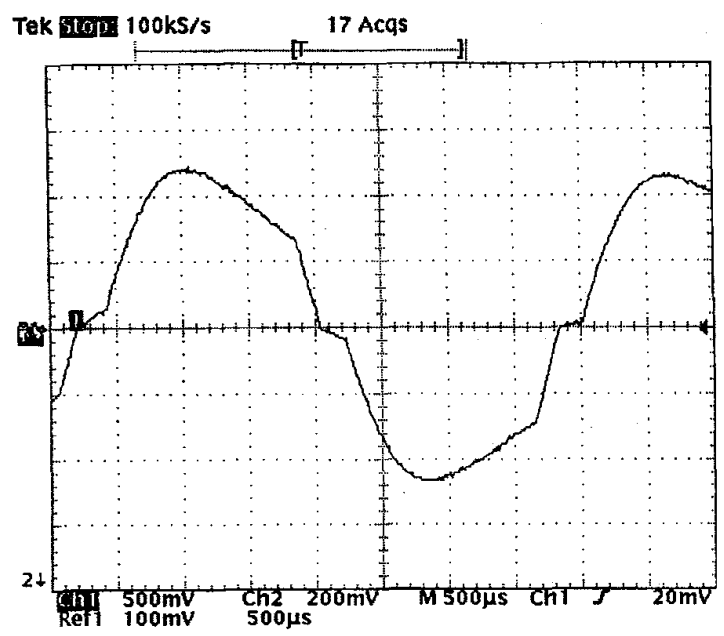

(b)

Fig. 10. Current waveforms at $1500 \mathrm{rpm}(10 \mathrm{~A} / \mathrm{div}, 500 \mu \mathrm{s} / \mathrm{div})$. (a) Simulation. (b) Experimental. 
TABLE I

TECHNICAL DATA

\begin{tabular}{ll}
\hline \hline Rated power & $1.5 \mathrm{~kW}$ \\
Rated voltage & $2 \times 48 \mathrm{~V}$ \\
Rated speed & $500 \mathrm{rpm}$ \\
Rated phase current & $26 \mathrm{~A}$ \\
Number of phases & 5 \\
Class of insulaton & $\mathrm{E}$ \\
Winding type & Single layer \\
Number of poles & 22 \\
Number of slots & 20 \\
Number of coils & 10 \\
Turns per coil & 26 \\
Slot pitch & $1-2$ \\
Stator outer diameter & $175 \mathrm{~mm}$ \\
Rotor outer diameter & $84 \mathrm{~mm}$ \\
Stator inner diameter & $86 \mathrm{~mm}$ \\
Rotor inner diameter & $48 \mathrm{~mm}$ \\
Core length & $100 \mathrm{~mm}$ \\
Slot width & $7.4 \mathrm{~mm}$ \\
Slot height & $36 \mathrm{~mm}$ \\
Conductor size & $7 \times 1.06 \mathrm{~mm}$ \\
Resistance per phase & $0.054 \Omega$ \\
Inductance per phase & $1.29 \mathrm{mH}$ \\
Magnet material & $\mathrm{Nd}-\mathrm{Fe}-\mathrm{B}$ \\
Magnet height & $5 \mathrm{~mm}$ \\
\hline &
\end{tabular}

\section{CONCLUSION}

A new optimal-efficiency control approach for constantpower operation of a phase-decoupling PM brushless DC motor is proposed and implemented. Since the proposed approach is so general, it can readily be extended to other PM brushless DC and AC motors. The approach possesses some distinct advantages: it optimizes the system efficiency of the motor drive; it does not require a complicated loss model; it is insensitive to system parameter variations; and it maintains constant-power operation with low torque ripple.
[1] C.C. Chan, J.Z. Jiang, G.H. Chen and K.T. Chau, "Computer simulation and analysis of a new polyphase multipole motor drive," IEEE Trans. Ind. Electron., vol. 40,1993 , pp. $570-576$.

[2] C.C. Chan, J.Z. Jiang, G.H. Chen, X.Y. Wang and K.T. Chau, "A novel polyphase multipole square-wave permanent magnet motor drive for electric vehicles," IEEE Trans. Ind. Applicat., vol. 30, 1994, pp. 1258-1266.

[3] C.C. Chan, J.Z. Jiang, W. Xia and K.T. Chau, "Novel wide range speed control of permanent magnet brushless motor drives," IEEE Trans. Power Electron., vol. 10, 1995, pp. 539-546.

[4] T.M. Jahns, "Flux-weakening regime operation of an interior permanent-magnet synchronous motor drive," IEEE Trans. Ind. Applicat., vol. 23, 1987, 681-689.

[5] S. Morimoto, Y. Takeda, T. Hirasa and K. Taniguchi, "Expansion of operating limits for permanent magnet motor by current vector control considering inverter capacity," IEEE Trans. Ind. Applicat., vol. 26, 1990, pp. 866-871.

[6] T.M. Jahns, "Torque production in permanent-magnet synchronous motor drives with rectangular current excitation," IEEE Trans. Ind. Applicat., vol. 20, 1984, pp. 803-813.

[7] N. Schofield, P.H. Mellor and D. Howe, "Fieldweakening of brushless permanent magnet motors for application in a hybrid-electric vehicle," Proc. 11th Int. Elect. Vehicle Symp., 1992, no. 8.13, pp. 1-11.

[8] R.S. Colby and D.W. Novotny, "An efficiency-optimizing permanent-magnet synchronous motor drive," IEEE Trans. Ind. Applicat., vol. 24, 1988, pp. 462-469. 